\title{
Perceptions of Iranian women regarding breast cancer screening behaviour
}

\author{
Seyedesaba Noori ${ }^{1}$ and Barbara C. Schouten
}

${ }^{1}$ Department of Communication Science, Amsterdam School of Communication Research, University of Amsterdam, Netherlands (Correspondence to: Barbara C. Schouten: b.c.schouten@uva.nl).

\begin{abstract}
Background: Breast cancer is the leading cause of death among women aged 20-59 years worldwide, with $58 \%$ of deaths occurring in less-developed countries. In the Islamic Republic of Iran, breast cancer constitutes $21 \%$ of all cancers, with an incidence rate of 22 per 100000 women.
\end{abstract}

Aims: Since research into breast cancer screening among Iranian women is scarce and results are contradictory, we aimed to explore women's' perceptions regarding breast cancer screening behaviour and provide insights into how breast cancer is perceived and approached. This could aid policy-makers in drafting effective interventions to stimulate women to perform regular screening.

Methods: We used the Health Belief Model as a theoretical framework. In-depth interviews with 22 women in Tehran were performed, based on a topic-list exploring the 6 constructs of the Health Belief Model: perceived barriers, perceived severity, perceived susceptibility, perceived benefits, self-efficacy and cues to action. Data-analysis was based on the Constructive Grounded Theory Method.

Results: The main barriers were fear, low priority and cultural values. Perceived severity was low for the majority of women, while perceived susceptibility was high for about half of them. Perceived benefit of screening was high for all women. Women's' self-efficacy was low when it came to breast self-examination. Talking about breast cancer screening and having somebody in their environment adopting screening behaviour were important cues for taking up breast cancer screening. Conclusions: Interventions should focus on diminishing barriers and increasing women's' self-efficacy and interpersonal communication about breast cancer screening.

Keywords: Iran, breast cancer, breast cancer screening, Health Belief Model.

Citation: Noori S; Schouten BC. Perceptions of Iranian women regarding breast cancer screening behaviour. East Mediterr Health J. 2018;24(12):11651171. https://doi.org/10.26719/emhj.18.018

Received: 02/08/16; accepted: 23/0717

Copyright (C) World Health Organization (WHO) 2018. Some rights reserved. This work is available under the CC BY-NC-SA 3.0 IGO license (https:// creativecommons.org/licenses/by-nc-sa/3.o/igo).

\section{Introduction}

Breast cancer is the leading cause of death among women aged $20-59$ years worldwide (1), with $58 \%$ of breast cancer-related deaths occurring in less-developed countries (2). In the Islamic Republic of Iran, breast cancer constitutes $21 \%$ of all cancers $(3,4)$ with an annual incidence of 22 per 100000 women (5). Most Iranian women are diagnosed with breast cancer between ages 35 and 44 years $(6,7)$, which is about 10 years younger than their Western counterparts (8). A large proportion of breast cancer is curable if diagnosed in an early stage (9). However, previous studies have shown that many Iranian women are diagnosed with advanced stages of breast cancer when no treatment can be provided, indicating the importance of giving continued attention to early detection (9-11).

To be able to design effective interventions to enhance breast cancer screening behaviour (i.e. breast self-examination (BSE) and clinical breast examinations), insight into the determinants of this behaviour is necessary. However, studies on this topic among Iranian women are scarce and have yielded some contradictory findings. For instance, while some studies showed that Iranian women have adequate knowledge about breast cancer screening methods (12), others indicated the reverse $(6,9)$. Furthermore, some studies found that women with a family history of breast cancer are more likely to go for breast cancer screening $(5,13)$, while others showed that a positive family history did not influence screening behaviour (9,12). Indeed, Rastad, Khanjani and Kalantari found that despite having serious signs of breast cancer, Iranian women might still not be willing to visit a doctor because potential subsequent appointments might cause them to sacrifice their family responsibility and job commitments (13), a barrier also reported in another study (14). In contrast, Iranian women reported a higher probability of performing BSE if they knew about the benefits, indicating that perceived benefits are positively associated with breast cancer screening behaviour (15). Effective doctor-patient communication and social support might motivate Iranian women to adopt breast cancer screening behaviour too (14).

Given the scarce and contradictory results, this study aimed explore Iranian women's' perceptions regarding breast cancer screening behaviour. By conducting a qualitative and theory-based study, additional insights can be gained into how breast cancer is perceived and 
approached in the Islamic Republic of Iran, which could help policy-makers in drafting effective interventions to stimulate women to perform regular breast cancer screening.

\section{Methods}

\section{Participants}

Purposive sampling was used because participants had to fulfil certain characteristic (16). They had to be 30 years or older, the age that Iranian women should start preforming breast cancer screening, and willing to be interviewed about breast cancer screening. To achieve a broad spectrum of perceptions, we aimed to recruit a heterogeneous sample comprising women from various sociodemographic backgrounds (e.g. marital status, education level, employment status; see Table 1 for characteristics of the participants). Around half of the participants were recruited via email and telephone using the social network of the first author. Those participants introduced us to the next interviewees, by making use of their own social networks. The number of participants was determined by the principle of data saturation (17), i.e. when no further themes are emerging in addition to existing conceptual categories (18). Data saturation in this study was reached when 22 women living in Tehran had been interviewed. Participants were between 30 and 67 years old and all of them were Muslim.

\section{Interviews}

Before conducting each interview, an informed consent form explaining the subject of the study and participants' right to withdraw from the study at any time was read and signed by all participants. Participants were interviewed alone in their chosen location, either at home or at work, in the local language (i.e. Farsi). The interviews lasted around 1 hour and were all audiotaped. All interviews were held during March-June 2016. The study was approved by the ethical committee of the Department of Communication Science, University of Amsterdam.

A topic list was developed based on the constructs of the Health Belief Model (HBM), a model developed to explain why individuals (fail to) participate in health behaviours (19). The HBM has been successfully used in several public health fields, including breast cancer screening (4), and comprises 6 constructs. The topic list started with some general questions about the participants' background characteristics and a closed question assessing their perception of their general health as good, moderate or bad. This was followed by questions on the 6 general HBM constructs: perceived barriers (e.g. 'Are there any barriers for you to perform breast cancer screening?'), perceived severity (e.g. 'How severe do you think breast cancer might be for you?'), perceived susceptibility (e.g. 'Do you think you are at risk of developing breast cancer?'), perceived benefits (e.g. 'What do you think the benefits are of having a breast cancer check-up?'), self-efficacy (e.g. 'Do you think that you are able to check your breasts on your own?'), and cues to action (e.g. 'Do you talk about having a breast cancer check-up with your husband?'). All questions were followed by open follow-through questions to stimulate participants to reflect on the topic.

\section{Data analysis}

The Constructive Grounded Theory Method was applied to analyse the data (20), using the logic of induction to generate new theory from data in a repetitive and evolving process (21). In this method, emphasis is placed on respondents' subjective experiences and feelings. All interviews were transcribed and translated into English, and coded in 2 stages. In the first stage, initial coding was applied in which each piece of data was examined line by line to produce as many codes as possible to identify all conceptual possibilities (22). In the second phase, focused coding was applied to group the initial codes under the 6 main categories of the topic list. Hence, the initial codes that referred to 1 of the 6 themes were clustered together and labelled under that theme.

To ensure reliability and validity, 3 transcripts were coded independently by the first and second author. Codings were discussed until mutual agreement was achieved. Subsequently, 2 more transcripts were coded. No differences in coding emerged between the researchers on these 2 transcripts. Consequently, the remainder of transcripts were coded by the first author. In addition, a member check was performed on 9 participants by sending them Farsi versions of the transcriptions to check for accuracy. Only minor changes with regard to the content and transposition of sentences were applied.

\section{Results}

\section{Themes}

Table 2 shows the definitions of each construct and a summary of the themes which emerged from the interviews using the HBM as theoretical framework.

\section{Perceived barriers}

Low priority, fear, cultural values and an inadequate doctor-patient relationship emerged as main barriers to adopting BSE or clinical breast examinations. All participants reported that they give insufficient priority to taking care of their health and adopting breast cancer screening behaviour. Half of them stated that the well-being of other family members (i.e. husband and children) is of higher priority for them. For example, one of the participants said: "Iranian women put everybody before themselves. They take care of their husband and children first then take care of themselves."

Fear was identified by the majority of participants to be an important barrier, with fear of knowing that one could be diagnosed with breast cancer being the most frequently mentioned type. To illustrate, one of the participants said: "I have never been to a doctor for breast cancer screening. It scares me a lot. Even finding one lump in my body scares me and I cannot take it. That is why my feet don't even move to go to a doctor for breast cancer screening." Fear of knowing that one has breast cancer can be accompanied by fear of the future because 


\begin{tabular}{|c|c|}
\hline \multicolumn{2}{|c|}{ Table 1 Characteristics of the participants $(n=22)$} \\
\hline Characteristic & $\%$ \\
\hline Mean (SD) age (years) & $40.8(12.5)$ \\
\hline Age range (years) & $30-67$ \\
\hline \multicolumn{2}{|l|}{ Marital status } \\
\hline Married & 50.0 \\
\hline Single/divorced/widowed & 50.0 \\
\hline \multicolumn{2}{|l|}{ No. of children } \\
\hline 0 & 59.0 \\
\hline 1 & 27.3 \\
\hline 2 & 4.6 \\
\hline 3 & 9.1 \\
\hline \multicolumn{2}{|l|}{ Perceived general health } \\
\hline Bad & 22.7 \\
\hline Moderate & 40.9 \\
\hline Good & 36.4 \\
\hline \multicolumn{2}{|l|}{ Education } \\
\hline High school diploma & 22.7 \\
\hline Higher education & 77.3 \\
\hline \multicolumn{2}{|l|}{ Occupation } \\
\hline Housewife & 27.2 \\
\hline Employed & 72.8 \\
\hline
\end{tabular}

of being ill. Uncertainty about the chances of survival and about how to deal with the disease hinders breast cancer screening behaviour. In addition, fear of the reaction of others, such as upsetting others or evoking their pity, was mentioned as a barrier by a few participants. Although these different types of fear prevented participants from adopting breast cancer screening, all stated that they would make themselves overcome their fears and visit a doctor when they feel that something is wrong with their breasts.

Waiting until an illness occurs before going for treatment is an element of a greater barrier related to Iranian cultural values. Most participants supported the value of postponing searching for a solution until something bad (e.g. an illness) happens because they believe that they should live in the moment. Participants associated this "living in the moment" attitude to Iranian culture and the way people are brought up, which leads to a preference for blocking "bad" thoughts. Thinking about illnesses such as breast cancer is an example of a bad thought that should be avoided. Many participants pointed out that they believed that by thinking about bad things, they would cause these bad things to happen. Hence, this caused them to avoid such thoughts. For example, one woman said: "My husband tells me not to think about breast cancer too much, because you know when you think about something it would happen to you". Hence, the common belief "whatever you think about might happen to you" prevents Iranian women from adopting breast cancer screening behaviour.
Some participants mentioned that an inadequate doctor-patient relationship is a barrier to adopting breast cancer screening. According to them, gynaecologists do not sufficiently encourage women to adopt breast cancer screening. Moreover, the possibility of a wrong diagnosis hinders women's adoption of breast cancer screening due to the distrust in doctors created. To illustrate, one of the participants said: "My father-in-law was wrongly diagnosed with a disease. We were very worried till it turned out that it was just a wrong diagnosis. That is why I do not trust doctors very much."

\section{Perceived severity}

A small majority believed that breast cancer is not a severe disease because they perceive it to be a curable cancer if diagnosed in an early stage. Five participants considered breast cancer to be a severe disease, but only if one is diagnosed in an advanced stage when no treatment can be provided any more. In addition, there was a third group of 4 women who believed that breast cancer was a severe disease without taking its stage into account. This group attributed having breast cancer with both clinical consequences, such as being in severe pain during treatment, and social consequences, among which were disturbances of everyday life due to having cancer and breast cancer being a threat to feminine beauty, which is posed by the possibility of having to remove the breast(s). As one participant explained: "I think breast cancer is a very severe disease. I associate breast cancer with breast removal. You might survive from cancer, but you have lost your breast and it is not replaceable. Breasts are signs of femininity and beauty for women."

\section{Perceived susceptibility}

Perceived susceptibility was low for about half of the participants due to not having a family history of the disease. They also gave no weight to other factors that could put them at risk for developing breast cancer. Only 2 participants saw themselves at high risk of getting breast cancer due to a positive family history. The other participants, who did not have a positive family history of breast cancer, did see themselves at risk of developing breast cancer because of its high prevalence in the country. They said that due to risk factors such as air pollution, stress and bad diet, it would be illogical to merely consider having a positive family history of breast cancer as a potential risk factor. One of the participants stated: "In my family, I do not have a positive family history of breast cancer. But genetics is one factor. There are other factors such as stress, air pollution and bad diet, which contribute to breast cancer. So, I see myself at risk of developing breast cancer."

\section{Perceived benefits}

Facilitating early detection of breast cancer led to high perception of the benefits of screening behaviours by all participants. They believed early diagnosis not only leads to quicker and easier treatment of the disease but also to peace of mind about their health status. One of the par- 
Table 2 Health belief model determinants and emerged themes for perceptions of Iranian women regarding breast cancer screening behaviour

\begin{tabular}{|c|c|c|}
\hline Determinant & Theme & Sample quotes \\
\hline \multirow{4}{*}{$\begin{array}{l}\text { Perceived barriers } \\
\text { Beliefs regarding whether one can overcome } \\
\text { difficulties or negative consequences of adopting a } \\
\text { health behaviour }\end{array}$} & Low priority & $\begin{array}{l}\text { I usually pay attention to my child and my husband's health } \\
\text { first and my own health is my second concern. }\end{array}$ \\
\hline & Fear & $\begin{array}{l}\text { I am scared of doing sonography. I am scared of knowing } \\
\text { that there is something wrong with my breasts. }\end{array}$ \\
\hline & Cultural values & $\begin{array}{l}\text { I believe that people will attract whatever they think about. } \\
\text { So, I try not to think that I might get breast cancer, instead } \\
\text { I try to think that I would never get breast cancer... I try to } \\
\text { want good things for myself. }\end{array}$ \\
\hline & $\begin{array}{l}\text { Inadequate doctor-patient } \\
\text { relationship }\end{array}$ & $\begin{array}{l}\text { Gynaecologists do not encourage women to have } \\
\text { sonography or mammography. For example, they do not } \\
\text { ask a patient about the last time she had a sonography or a } \\
\text { mammography examination or whether she has ever had } \\
\text { it. Nor they remind a patient that they should adopt breast } \\
\text { cancer screening after a certain age. Only some of them } \\
\text { examine their patients' breasts. }\end{array}$ \\
\hline
\end{tabular}

Perceived severity

Beliefs about the seriousness of developing a

disease, consisting of two dimensions; evaluation

of medical consequences and evaluation of social consequences of a disease
Treatable in early stage

I do not think that breast cancer is a severe disease, because if it is diagnosed in its early stage, the person still has a high chance of survival, because breast cancer can be easily cured in that stage.

\section{Pain}

Threat to femininity

Disturbance

Breast cancer is a severe disease, because one has to deal with a long-term pain.

You may lose your breast, the feminine part of your body. Nothing can replace it.

Having breast cancer disturbs one's daily routine and forces her to deal with stressful issues.

Perceived susceptibility

Individuals' subjective risk perceptions of developing a disease
No family history

High prevalence

\section{We do not have a history of cancer in our family, so I do not} see myself at risk of getting it.

\section{Perceived benefits}

Evaluation of a particular health behaviour in terms of benefits and effectiveness in curing the disease

Self-efficacy

Individuals' perceived ability and capability to adopt a health behaviour

Cues to action

Internal or external stimuli that motivate one to take action
Curability because of early detection

Not able to perform breast

self-examination

Able to make health-related decisions

Talking about breast cancer

Observing a person undergoing breast cancer screening
I do see myself at risk of getting breast cancer, because I see a lot of women dealing with it. Nowadays, in Iran cancer could happen to anybody. It has become like a tsunami.

I think breast cancer screening is beneficial. It helps you find out about the disease early. Breast cancer might be curable if it is diagnosed in the early stage.

I do not perform breast self-examination, because I am not able to understand the differences between the lumps inside my breast. And this makes me more worried and nervous. I decide about my health on my own.

I talk about breast cancer with my mother. She always emphasizes on taking care of our breasts.

I think if somebody in my family decides to examine her breasts for cancer, I might get motivated to do so as well. For example, if my sister decides to screen her breasts for cancer I might decide to do it as well. Because it makes me start thinking about my health. ticipants stated: "One of the benefits of the breast cancer screening is that it makes you relaxed and sure about your health. It gives you peace of mind and you can enjoy your life."

\section{Self-efficacy}

Low self-efficacy was reported by 9 participants with regard to performing BSE. These women indicated that they were not able to distinguish between healthy and unhealthy lumps inside their breasts. In addition, although participants stated that they have the autonomy to make health-related decisions on their own, the decision-making process can be facilitated by support from their family members. Receiving support and confirmation strengthens their decision to adopt a health behaviour, as the following illustrates: "I decide about my health with the help of my husband. He encourages me to do my check-ups." 


\section{Cues to action}

Two themes emerged from the interviews which function as cues to action for breast cancer screening behaviour: talking about breast cancer detection behaviour with family and friends and observing somebody in their environment who has taken up breast cancer examinations. Participants believed that the high prevalence of breast cancer has made it easier for people to talk about the disease compared to a few years earlier. Although 7 participants believed that some people are still not willing to talk about breast cancer due to the negative feelings surrounding it, the majority stated that they talk about breast cancer with family and close friends and that these discussions motivate them to take up breast cancer screening. In addition, seeing somebody in their environment who has taken up breast cancer screening is another cue to action, because observing someone adopting breast cancer screening makes them worried about their own health and motivates them to do the same.

\section{Discussion}

Our findings indicate that the most important barriers to adopting breast cancer screening behaviour by Iranian women living in Tehran are fear, low priority and cultural values. Previous studies have also identified fear, in particular fear of knowing that one has breast cancer, as an important factor that hinders breast cancer screening by Iranian women $(13,14,23-25)$. The finding that Iranian women in Tehran prioritize their family above their own health is corroborated by previous studies too $(13,14)$. Our results suggest that giving priority to family members seems to be rooted in the culture and societal expectations in the Islamic Republic of Iran, possibly to the detriment of the women's own health. However, more quantitative research among different respondents (e.g. women living outside Tehran) is needed to be able to confirm the extent to which this is indeed the case. This study also identified a new barrier, namely the tendency to live in the moment and avoid bad thoughts. Living in a socially, politically and economically unstable country has turned the coping mechanism of living in the moment into a cultural value, upon which Iranians base their everyday behaviour. Thinking about bad incidents is socially rejected and avoiding bad thoughts is promoted as a good way of living. These cultural values are a threat to preventive behaviour, because they replace preventive behaviour with treatment, discouraging Iranian women from preventing illnesses in advance.

The majority of the interviewees did not perceive breast cancer to be a severe disease because they believed that, due to the progression of medical science, breast cancer can be treated more easily than before. Only if breast cancer is diagnosed in advanced stages it is deemed severe by some interviewed women. Only 4 participants, who believed breast cancer to be severe, considered both the clinical and social consequences of having this disease. Slightly more women in this study perceived themselves to be highly susceptible to the disease, some due to having a positive family history of breast cancer, a finding also reported in previous research (5). Even in the absence of a positive family history though, they find themselves susceptible to breast cancer because of its high current prevalence. In fact, the shared belief among most participants was that a positive family history of breast cancer is no longer the determining factor of the disease as they considered environmental factors, such as air pollution and bad diet, more important risk factors.

Nine participants reported low self-efficacy for BSE. The impact of self-efficacy on performing BSE has been reported in previous research (23) and highlights the importance of implementing educational programmes that teach women how to examine their breasts and become more confident about this detection method. Although the participants in this study reported high selfefficacy with regard to decision-making concerning their health, they admitted that receiving support from family members makes it easier for them to implement their health decisions. In the same vein, talking about breast cancer with family and friends and having somebody in their environment who examines her breasts can serve as powerful cues to action to take up breast cancer screening because this may cause women to become more aware of their own health. Thus, health interventions should motivate women to adopt breast cancer screening by promoting interpersonal communication about the topic.

In conclusion, the findings of this study can assist policy-makers in creating effective health interventions to increase the adoption of breast cancer screening behaviour by Iranian women. Iranian women have positive beliefs about the benefits of breast cancer screening and see themselves as susceptible to the disease, but their screening behaviour is hindered because they give low priority to their health and have deterrent cultural values. Interventions should increase their belief that their own health is equally important as the health of their family members, and should focus on the benefits and importance of preventive behaviour.

Funding: None.

Competing interests: None declared. 


\section{Perceptions des femmes iraniennes au sujet des comportements face au dépistage du cancer du sein}

Résumé

Contexte : Le cancer du sein est la principale cause de mortalité chez les femmes de 20 à 59 ans dans le monde. Cinquantehuit pour cent des décès se produisent dans les pays les moins développés. En République islamique d'Iran, les cancers du sein représentent $21 \%$ de tous les cancers et le taux d'incidence est de 22 pour 100000 femmes.

Objectif : Les recherches sur le dépistage du cancer du sein chez les femmes iraniennes sont rares et leurs résultats sont souvent contradictoires. La présente étude visait donc à étudier les perceptions des femmes concernant les comportements face au dépistage du cancer du sein et à fournir des indications sur la façon dont le cancer du sein est perçu et abordé. Ses résultats pourraient aider les décideurs politiques à élaborer des interventions efficaces pour encourager les femmes à pratiquer régulièrement le dépistage.

Méthodes: Nous avons utilisé comme cadre théorique le modèle de croyances relatives à la santé. Des entretiens approfondis ont été réalisés à Téhéran auprès de 22 femmes. Ils s'appuient sur une liste de sujets explorant les six composantes du modèle de croyances relatives à la santé, soit les obstacles, la gravité, la vulnérabilité et les avantages perçus, ainsi que l'auto-efficacité et les indices à l'action. L'analyse de données était fondée sur la méthodologie constructiviste de la théorie enracinée.

Résultats : Les principaux obstacles étaient la peur, la faible priorité accordée au dépistage et les valeurs culturelles. La gravité perçue était faible pour la majorité des femmes et la vulnérabilité perçue était élevée pour environ la moitié d'entre elles. Les avantages perçus du dépistage étaient élevés pour toutes les femmes. Les femmes présentaient une faible autoefficacité en ce qui concerne l'auto-examen des seins. Parler du dépistage du cancer du sein et avoir auprès de soi une personne qui adopte des comportements de dépistage ont été identifiés comme des éléments qui incitent les femmes à pratiquer le dépistage du cancer du sein.

Conclusions : Les interventions devraient mettre l'accent sur la réduction des obstacles ainsi que sur l'amélioration de l'auto-efficacité des femmes et de la communication interpersonnelle au sujet du cancer du sein.

$$
\begin{aligned}
& \text { تصورات النساء الإير انيات حول سلوك تحري سرطان الثدي } \\
& \text { سيدة صبا نوري، باربر ا كاترين شوتن } \\
& \text { الخالاصة }
\end{aligned}
$$

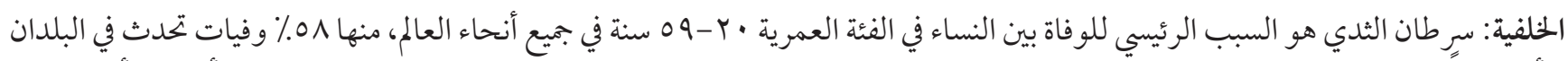

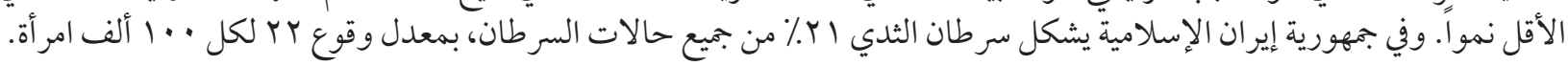

الأهداف:

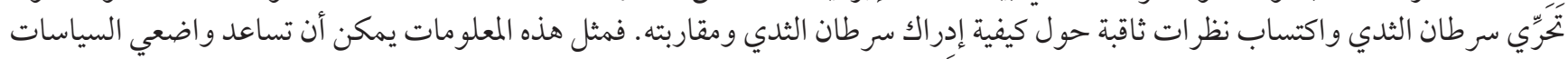

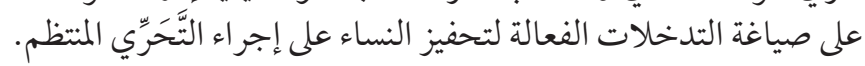
طرق البحث: استخدمنا نموذج المعتقدات الصحية على أنها إطار نظري. فأجرينا مقابلات معمقة مع ب ب امرأة في طهران، استندنا فيها إلى قائمة

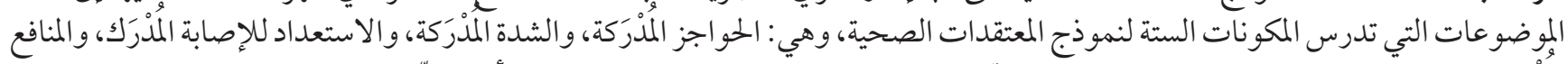

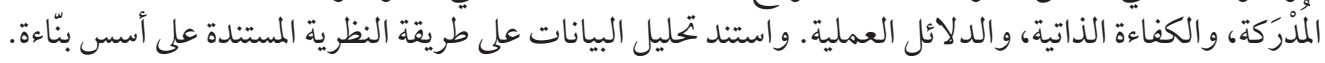

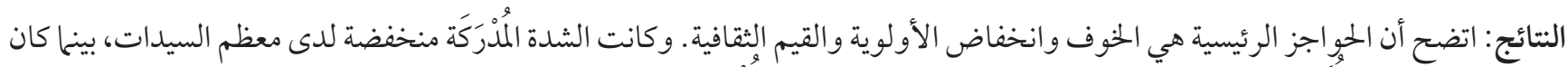

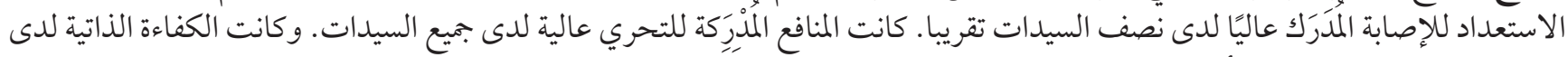

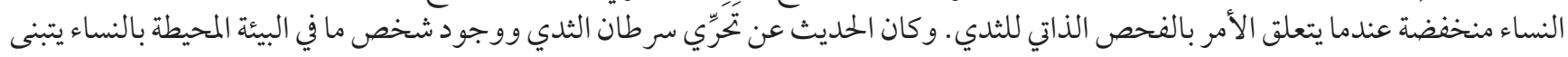

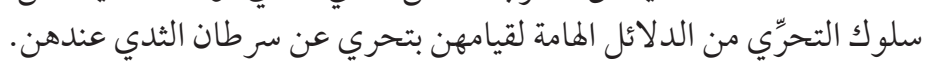

الاستنتاجات: ينبغي أن تركز التدخلات على تخفيف الحواجز وزيادة الكفاءة الذاتية للنساءوعلى الاتصالات بين الأشخاص حول تحرّي سرطان الثدي.

\section{References}

1. Women's health. Geneva: World Health Organization; 2013 (http://www.who.int/mediacentre/factsheets/fs334/en/, accessed 22 March 2018).

2. Breast cancer: prevention and control. Breast cancer burden. Geneva: World Health Organization; 2018 (http://www.who.int/ cancer/detection/breastcancer/en/indexı.html, accessed 9 May 2018). 
3. Babu GR, Samari G, Cohen SP, Mahapatra T, Wahbe RM, Mermash S. et al. Breast cancer screening among females in Iran and recommendations for improved practice: a review. Asian Pac J Cancer Prev. 2011;12:1647-55. PMID:22126539

4. Noroozi A, Jomand T, Tahmasebi R. Determinants of breast self-examination performance among Iranian women, an application of the Health Belief Model. J Cancer Educ. 2010;26(2):365-74.

5. Jarvandi S, Montazeri A, Harirchi I, Kazemnejad, A. Beliefs and behaviours of Iranian teachers toward early detection of breast cancer and breast self-examination. Public Health. 2002 Jul;116(4):245-9. https://doi.org/10.1038/sj.ph.1900854 PMID:12087485

6. Heidari Z, Mahmoudzadeh-Sagheb HR, Sakhavar N. Breast cancer screening knowledge and practice among women in southeast of Iran. Acta Med Iran. 2008;46(4):321-8.

7. Taleghani F, Yekta ZP, Nasrabadi AN. Coping with breast cancer in newly diagnosed Iranian women. J Adv Nurs. 2006 May;54(3):265-72, discussion 272-3. https://doi.org/10.1111/j.1365-2648.2006.03808_1.x PMID:16629910

8. Harirchi I, Ebrahimi M, Zamani N, Jarvandi S, Montazeri A. Breast cancer in Iran: a review of 903 case records. Public Health. 2000 Mar;114(2):143-5. PMID:10800155

9. Hajian S, Vakilian K, Najabadi K, Hosseini J, Mirzaei HR. Effects of education based on the Health Belief Model on screening behavior in high risk women for breast cancer, Tehran, Iran. Asian Pac J Cancer Prev. 2011;12(1):49-54. PMID:21517230

10. Harirchi I, Ghaemmaghami F, Karbakhsh M, Moghimi R, Mazaherie H. Patient delay in women presenting with advanced breast cancer: an Iranian study. Public Health. 2005 Oct;119(10):885-91. https://doi.org/10.1016/j.puhe.2004.11.005 PMID:15913679

11. Mousavi SM, Montazeri A, Mohagheghi MA, Jarrahi AM, Harirchi I, Najafi M, et al. Breast cancer in Iran: an epidemiological review. Breast J. 2007;13:383-91. https://doi.org/10.1111/j.1524-4741.2007.00446.x

12. Montazeri A, Vahdaninia M, Harirchi I, Harirchi AM, Sajadian A, Khaleghi F, et al. Breast cancer in Iran: need for greater women awareness of warning signs and effective screening methods. Asia Pac Fam Med. 2008;7(6):1-7. https://doi.org/10.1186/1447056X-7-6

13. Rastad H, Khanjani N, Kalantari Khandani B. Causes of delay in seeking treatment in patients with breast cancer in Iran: A qualitative content analysis study. Asian Pac J Cancer Prev. 2012;13(9):4511-5. https://doi.org/10.7314/APJCP.2012.13.9.4511 PMID:23167370

14. Lamyian M, Hydarnia A, Ahmadi F, Faghihzadeh S, Aguilar-Vafaie ME. Barriers to and factors facilitating breast cancer screening among Iranian women: a qualitative study. East Mediterr Health J. 2007 Sep-Oct;13(5):1160-9. https://doi. org/10.26719/2007.13.5.1160 PMID:18290410

15. Hashemian AH, Hajizadeh E, Kazemnejad A, Atri M, Mehdipour P. Penetrance of BRCA1/BRCA2 specific gene mutations in Iranian women with breast cancer. Saudi Med J. 2009 Jan;30(1):41-4. PMID:19139771

16. Riffe D, Lacy S, Fico FG. Analyzing media messages: using quantitative content analysis in research (2nd ed.). Mahwah, New Jersey: Lawrence Erlbaum Associates; 2005.

17. Glaser BG, Strauss A. The discovery of grounded theory: strategies for qualitative research. Chicago: Aldine; 1967.

18. Francis JJ, Johnston M, Robertson C, Glidewell L, Entwistle V, Eccles MP, Grimshaw JM. What is an adequate sample size? Operationalising data saturation for theory-based interview studies. Psychol Health. 2010 Dec;25(10):1229-45. https://doi. org/10.1080/08870440903194015 PMID:20204937

19. Janz NK, Becker MH (1984). The health belief model: A decade later. Health Educ Q. 1984;11(1):1-47. https://doi. org/10.1177/109019818401100101 PMID:6392204

20. Charmaz K. Grounded theory: Objectivist and constructivist methods. In: Denzin NK, Lincoln YS (Eds.), Strategies of qualitative inquiry, London: Sage; 2000:249-91.

21. Kok Ong B. Grounded theory method (GTM) and the abductive research strategy (ARS): a critical analysis of their differences. Int J Soc Res Methodol. 2012;15(5):417-32. https://doi.org/10.1080/13645579.2011.607003

22. Birks M, Mills J. Data analysis in grounded theory. In: Seaman J, ed. Grounded theory: a practical guide. London: Sage; 2011:85107.

23. Yarbrough S, Braden C. Utility of health belief model as a guide for explaining predicting breast cancer screening behaviors. J Adv Nurs. 2001;33:677-88. https://doi.org/10.1046/j.1365-2648.2001.01699.x PMID:11298205

24. Tastan S, Iyigün E, Kilıc A, Unver V. Health beliefs concerning breast self-examination of nurses in Turkey. Asian Nurs Res. 2011;5(3):151-6. https://doi.org/10.1016/j.anr.2011.09.001

25. Parsa P, Kandiah M. Breast cancer knowledge, perception and breast self-examination practices among Iranian women. Int Med J. 2005:4(2):17-24. 